Recebido em: 24-03-2017 Aceito em: 05-05-2017

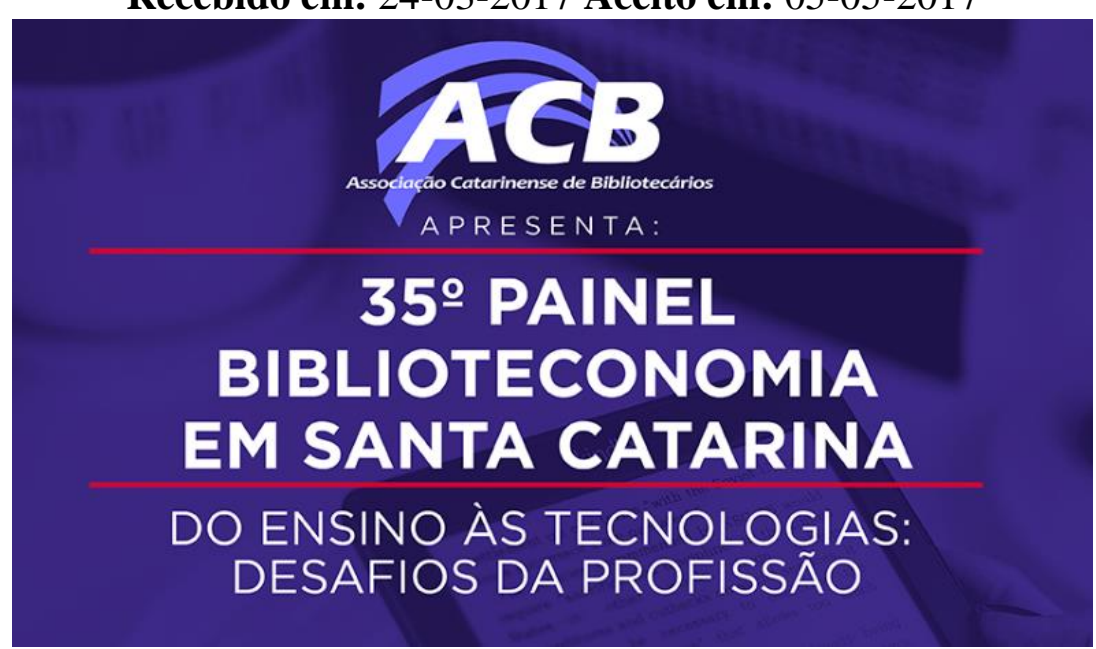

\title{
COMPETÊNCIAS DO BIBLIOTECÁRIO NO PROCESSO DE REFERÊNCIA EDUCATIVO DE BIBLIOTECAS UNIVERSITÁRIAS
}

\author{
Sirlene Pintro ${ }^{1}$ \\ Gregório Varvakis ${ }^{2}$ \\ Danielly Oliveira Inomata ${ }^{3}$
}

\begin{abstract}
Resumo: O serviço de referência é uma das atividades centrais das bibliotecas e passa por grandes transformações decorrentes do avanço tecnológico. Nesse contexto, os bibliotecários que atuam no serviço de referência passam a assumir novas funções, o que exige o desenvolvimento de novas competências para que possam desenvolver suas atividades com qualidade. Levando em consideração esses aspectos, mostrou-se relevante a investigação das competências necessárias ao bibliotecário atuante nesse vertente do serviço de referência que se expande progressivamente, o processo de referência educativo. Identificaram-se e caracterizam-se as etapas do processo de referência e educativo e foram definidas as competências necessárias ao bibliotecário de referência em cada uma das etapas. Conclui-se que o conjunto definido de competências contribui para o aperfeiçoamento dos serviços prestados por unidades de informação que desenvolvem o processo de referência educativo.
\end{abstract}

Palavras-chave: Serviço de referência. Processo de referência educativo. Competências do bibliotecário.

\section{INTRODUÇÃO}

As bibliotecas universitárias têm como objetivo principal prover recursos e serviços informacionais para a comunidade universitária, sendo o conhecimento considerado o recurso fundamental nessa função, seja tanto do funcionamento da biblioteca, dos seus usuários e suas necessidades, como do acervo, das instalações, das tecnologias disponíveis, etc.

Como destaca Maponya (2004), o sucesso das bibliotecas universitárias está ligado às capacidades e competências do seu pessoal para atender às necessidades da comunidade universitária de forma mais

\footnotetext{
${ }^{1}$ Doutoranda em Ciência da Informação pelo Programa de Pós-Graduação em Ciência da Informação da Universidade Federal de Santa Catarina (PGCIN/UFSC).

${ }^{2}$ Doutor em Manufacturing Engineering pela Loughborough University of Technology (LBORO- Inglaterra).

${ }^{3}$ Doutoranda em Ciência da Informação pela Universidade Federal de Santa Catarina (PGCIN/UFSC). Mestre em Ciência da Informação pela Universidade Federal de Santa Catarina (PGCIN/UFSC).
} 
Revista ACB: Biblioteconomia em Santa Catarina, Florianópolis, v. 22, n. 2, ESPECIAL, p. 329-342, abr./ jul., 2017. Anais do $35^{\circ}$ Painel Biblioteconomia Santa Catarina.

Chapecó

eficiente e eficaz. Portanto, todos esses conhecimentos, juntos, levam à criação de novos conhecimentos e, por conseguinte, ao desenvolvimento de todo o processo de prestação de serviços aos usuários.

Outros fatores culminaram para as mudanças, por exemplo, a criação e desenvolvimento da Web, a evolução dos meios de comunicação, os ajustes na dimensão tempo e espaço, os modos de leitura e circulação das ideias. Em um movimento sincronizado, o mesmo ocorre com as bibliotecas, o fazer dos bibliotecários frente ao novo ambiente, emergindo novas funções, novos papéis e novas competências. Porém, como destaca Ferreira (2004), é importante que aproveite e use a experiência já adquirida, visto que a tecnologia não consegue replicar a interação humana que ocorre entre o bibliotecário e o usuário.

Este artigo faz um recorte e se debruça na análise das mudanças do serviço de referência, que conforme afirmam Alves e Faqueti (2002, p. 12) é fundamental considerar duas abordagens: a abordagem tradicional, "cujo papel central do serviço de referência seria a provisão da informação considerando que o objetivo da busca de informação é o produto" e a abordagem alternativa, "cujo foco é a orientação aos usuários na busca da informação e o objetivo é o processo".

Este aspecto pode ser justificado como aponta Silva (2008, p. 19), para quem a função e o espaço da biblioteca podem ser ampliados diante do dinamismo do profissional bibliotecário, visto que este pode atuar tanto "como orientador no uso do sistema de informação" quanto "como executor da pesquisa".

Desde modo, salienta-se que o serviço de referência necessita se basear em competências fundamentais e em experiências acumuladas, com vistas a agregar valor ao próprio serviço e à organização, satisfazendo os requisitos do usuário (DAVENPORT; JARVENPAA; BEERS, 1996; SCHREIBER et al., 2000; ABECKER et al., 2001; SEO et al., 2011) com vistas à melhoria da qualidade desse serviço.

O recorte que analisa apenas o serviço de referência se justifica pelo fato deste setor ser uma das atividades essenciais de uma biblioteca, por ser o bibliotecário de referência aquele responsável pelo front end da biblioteca, isto é, que mantém constante contato com os usuários. Esta justificativa já demonstra o valor da contribuição para a área da Biblioteconomia quando realiza uma análise das competências relacionadas ao bibliotecário no processo de referência, e para a Ciência da Informação quando sintetiza de que maneira os serviços resultantes de um fluxo informacional pode trazer melhoria para a prestação de serviços a usuários.

Este artigo tem como objetivo definir as competências necessárias ao bibliotecário atuante no Processo de Referência Educativo (PRE) de bibliotecas universitárias, diante das transformações ocorridas em suas funções nesse novo tipo de processo dentro do serviço de referência. 
Revista ACB: Biblioteconomia em Santa Catarina, Florianópolis, v. 22, n. 2, ESPECIAL, p. 329-342, abr./ jul., 2017. Anais do $35^{\circ}$ Painel Biblioteconomia Santa Catarina.

Chapecó

\section{METODOLOGIA}

Esta pesquisa caracteriza-se como bibliográfica, visto que foi “[...] desenvolvida a partir de material já elaborado, constituído principalmente de livros e artigos científicos” (GIL, 2008, p. 50) para o desenvolvimento teórico e conceitual do tema em questão.

Por meio de revisão de literatura foram identificadas e caracterizadas as etapas do PRE. Após a identificação e caracterização das etapas do PRE, ainda com base na literatura, foram definidas as competências (conhecimentos, habilidades e atitudes) necessárias ao bibliotecário em cada uma dessas etapas.

A busca na literatura revelou a existência de um extenso número de competências relacionadas ao bibliotecário, em diferentes setores e atividades de unidades de informação. Além disso, foram identificadas competências relacionadas aos bibliotecários atuantes em diversos contextos, tais como empresas e atividades de inteligência competitiva. Muitos termos utilizados na literatura eram distintos, mas possuíam o mesmo significado e estavam relacionados à mesma competência.

De posse de uma vasta relação de competências identificadas na literatura, analisou-se quais delas eram coerentes e relacionadas com as características de cada uma das etapas do PRE. As competências consideradas incompatíveis com tais características foram descartadas. Competências identificadas com termos distintos mas que possuíam o mesmo significado foram agrupadas sob a denominação de um único termo.

\section{COMPETÊNCIAS}

Na literatura é possível encontrar diversos conceitos de competência. No entanto, de acordo com Ropé e Tanguy (1997) é importante considerar que não é possível compreender a competência de forma separada da ação.

Nessa mesma linha, Fleury e Fleury (2000, p. 21) elaboram um conceito de competência como “[...] um saber agir responsável e reconhecido, que implica mobilizar, integrar, transferir conhecimentos, recursos, habilidades, que agreguem valor econômico à organização e valor social ao indivíduo". Na Figura 1, os autores ilustram essa definição de competências como fonte de valor, tanto para os indivíduos quanto para as organizações. 
Revista ACB: Biblioteconomia em Santa Catarina, Florianópolis, v. 22, n. 2, ESPECIAL, p. 329-342, abr./ jul., 2017. Anais do $35^{\circ}$ Painel Biblioteconomia Santa Catarina.

Chapecó

Figura 1 - Competências como fonte de valor para o indivíduo e para a organização

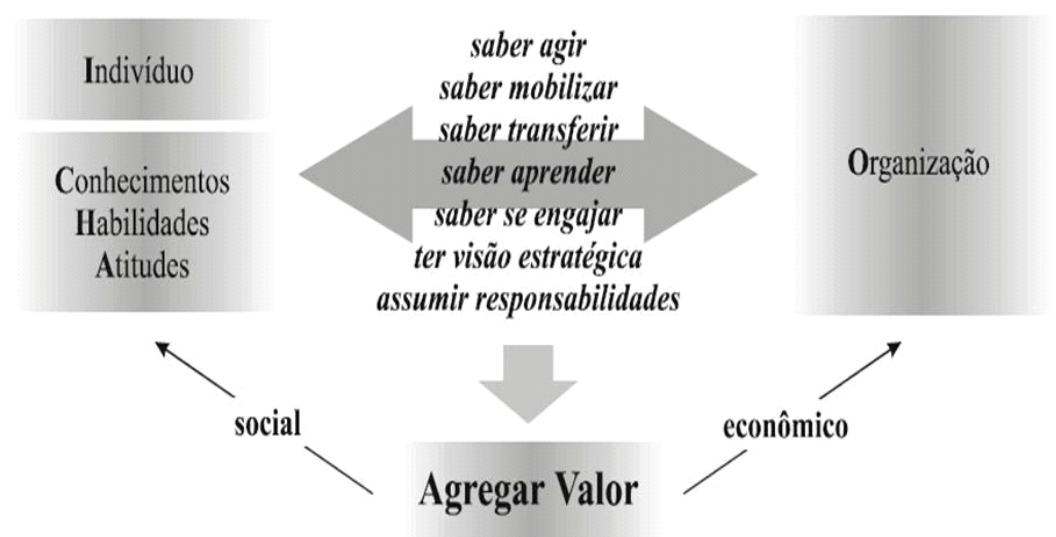

Fonte: Fleury e Fleury (2000, p. 21)

Para Amaral et al. (2008), a competência é desenvolvida com a utilização adequada dos conhecimentos (saber), das habilidades (saber fazer) e das atitudes (saber ser) do indivíduo, sendo que estes atributos devem apresentar a compatibilidade com as funções desempenhadas.

Da mesma forma, para Alexim e Brígido (2002, p. 22), a competência é a "Capacidade de articular e mobilizar condições intelectuais e emocionais em termos de conhecimentos, habilidades, atitudes e práticas, necessários para o desempenho de uma determinada função ou atividade, de maneira eficiente, eficaz e criativa, conforme a natureza do trabalho".

De maneira geral, quando se apresentam definições de competência, existem três dimensões clássicas que são citadas:

- conhecimentos (saber - acumulado pelo indivíduo);

- habilidades (saber-fazer - uso produtivo do conhecimento);

- atitudes (saber ser - relacionado a aspectos sociais e afetivos no trabalho).

Essa três dimensões da competência compõem a tríade conhecida como $\mathrm{CHA}(\mathrm{C}$ - conhecimentos / $\mathrm{H}$ - habilidades / A - Atitudes) e encontra-se ilustrada na Figura 2, a seguir. 
Figura 2 - As três dimensões da competência

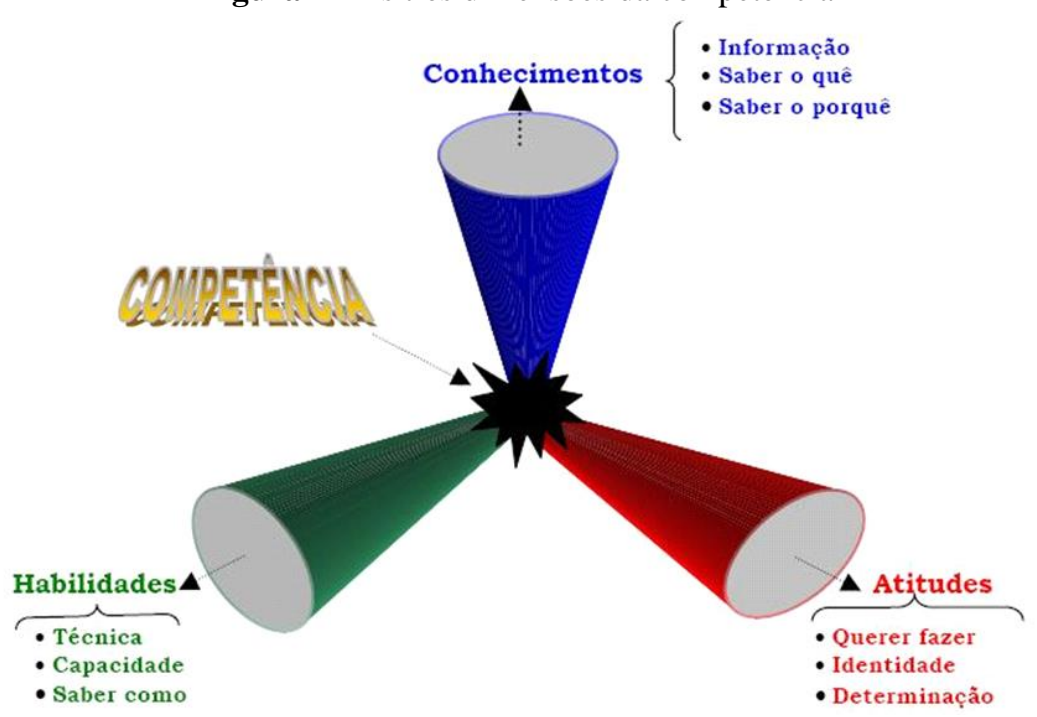

Fonte: Brandão e Guimarães (2001), adaptado de Durand (2000)

Com base nessas três dimensões, Durand (1998; 2000) desenvolveu um modelo genérico do conceito de competência, considerando que a competência é o conjunto de conhecimentos, habilidades e atitudes interdependentes e complementares, sendo que nesse conjunto ainda entram questões técnicas, a cognição e as atitudes relacionadas ao trabalho. As competências são desenvolvidas por meio da aprendizagem individual e coletiva e com o envolvimento simultâneo e interdependente das três dimensões.

Nesse processo de aprendizagem para o desenvolvimento da competência, o conhecimento é obtido pela recepção de dados externos como informações que são assimiladas. As habilidades se desenvolvem por meio da ação e as atitudes por meio da interação. (DURAND, 1998)

\section{O SERVIÇO DE REFERÊNCIA E O PROCESSO DE REFERÊNCIA EDUCATIVO}

O serviço de referência, de acordo com Ferreira (2004, p. 3), pode ser definido como “[...] o processo de identificar as necessidades de informação de um utilizador, facultar-lhe o acesso aos recursos e fornecer-lhe apoio apropriado para satisfação das suas necessidades [...]”. Já para Alves e Vidotti (2006, p. 1), o Serviço de Referência e Informação (SRI) busca “[...] garantir informações que atendam as necessidades informacionais dos usuários [...]”.

Grogan (1995, p. 50) esclarece que existe uma diferenciação entre os termos "Serviço de referência" e "Processo de Referência", sendo que o primeiro "[...] aplica-se à assistência efetivamente prestada ao usuário que necessita de informação [...]" e o último é utilizado “[...] para denominar, em sua totalidade, a atividade que envolve o consulente e durante a qual se executa o serviço de referência”. 
Revista ACB: Biblioteconomia em Santa Catarina, Florianópolis, v. 22, n. 2, ESPECIAL, p. 329-342, abr./ jul., 2017.

Anais do $35^{\circ}$ Painel Biblioteconomia Santa Catarina.

Chapecó

O serviço de referência apresenta um histórico de evolução, o qual é influenciado fortemente pelo desenvolvimento das tecnologias de informação e comunicação (TIC). De acordo com Cunha (2000), essas TIC possibilitam maior eficácia no atendimento do serviço de referência, pois influenciam nos métodos e nos enfoques utilizados pelos bibliotecários.

No entanto, apesar da forte influência das TIC no serviço de referência, Grogan (1995, p. 22) afirma que "O trabalho de referência, porém, é muito mais do que uma técnica especializada ou uma habilidade profissional. Trata-se de uma atividade essencialmente humana, que atende a uma das necessidades mais profundamente arraigadas da espécie, que é o anseio de conhecer e compreender”.

De acordo com Nunes e Santos (2007), a estrutura das bibliotecas universitárias demonstra de maneira mais clara as mudanças na prestação de serviços de informação, decorrentes do desenvolvimento tecnológico, com foco cada vez maior nas necessidades dos usuários.

Em pesquisa publicada anteriormente (PINTRO; INOMATA; VARVAKIS, 2014), verificou-se uma mudança no serviço de referência das Bibliotecas Universitárias, as quais vêm incorporado o processo de referência educativo. Nesse sentido, observou-se que o serviço de referência das Bibliotecas Universitárias passou a utilizar as tecnologias a seu favor, garantindo avanço e inovação na prestação de serviços.

Rostirolla (2006, p. 43) afirma que o Processo de Referência Educativo (PRE) “[...] caracteriza-se pela orientação e capacitação do usuário ou de um grupo de usuários no acesso e uso de fontes de informação sobre uma determinada área ou tema de interesse [...]”, podendo ser oferecido na forma presencial ou à distância. No PRE em Bibliotecas Universitárias, o bibliotecário de referência passa a ter novas funções, agindo como um educador para a utilização de recursos informacionais e oferecendo cursos e capacitações sobre esses recursos à comunidade universitária.

Para Assis (2002) o desenvolvimento e a difusão de novas tecnologias têm impacto sobre as funções já existentes.

O processo de recriação tem lugar quando o perfil das ocupações tradicionais se vê ampliado ou alargado por novos conhecimentos/habilidades na transição para as novas tecnologias, ao mesmo tempo em que alguns conhecimentos e habilidades deixam de integrá-lo. Não há uma ruptura entre as "novas" ocupações e as ocupações convencionais. Nesse sentido, a inovação técnica cria uma qualificação adicional que pode ser construída a partir de conhecimentos "antigos", que passam a constituir o ponto de partida da "nova" qualificação (ASSIS, 2002, p. 190).

Nesse cenário, o papel e qualificação do profissional da informação entram em discussão, visto que o seu campo de atuação é ampliado e redimensionado (ARRUDA; MARTELETO; SOUZA, 2000). Esse novo contexto de métodos e formas de trabalho, demanda o desenvolvimento de novas competências para o profissional da informação (LISTON; SANTOS, 2008). 
Revista ACB: Biblioteconomia em Santa Catarina, Florianópolis, v. 22, n. 2, ESPECIAL, p. 329-342, abr./ jul., 2017. Anais do $35^{\circ}$ Painel Biblioteconomia Santa Catarina.

Chapecó

Levando em consideração o exposto, neste estudo buscou-se identificar e definir quais as competências necessárias ao bibliotecário atuante no serviço de referência e, mais especificamente, no PRE de bibliotecas universitárias, diante das transformações em suas funções. Os resultados encontram-se especificados na seção a seguir.

\subsection{AS COMPETÊNCIAS DO BIBLIOTECÁRIO NO PROCESSO DE REFERÊNCIA EDUCATIVO}

O PRE é dimensionado por Rostirolla (2006) em quatro etapas:

1) Identificação do campo de conhecimento - identificação das necessidades informacionais do usuário ou grupo de usuários com a utilização de entrevista prévia;

2) Roteiro - seleção das fontes a serem acessadas e demonstradas e das palavras-chave pertinentes à área de interesse dos usuários;

3) Ensino/Aprendizagem - ocorrência do efetivo ensino sobre o acesso e uso das fontes e recursos informacionais anteriormente selecionados;

4) Feedback - avaliação do ensino-aprendizagem pelo bibliotecário em conjunto com o usuário ou grupo de usuários.

Na definição do PRE deste estudo, com vistas à definição das competências necessárias, foram consideradas as quatro etapas do processo apresentadas por Rostirolla (2006), o qual pode ser visualizado na Figura 3.

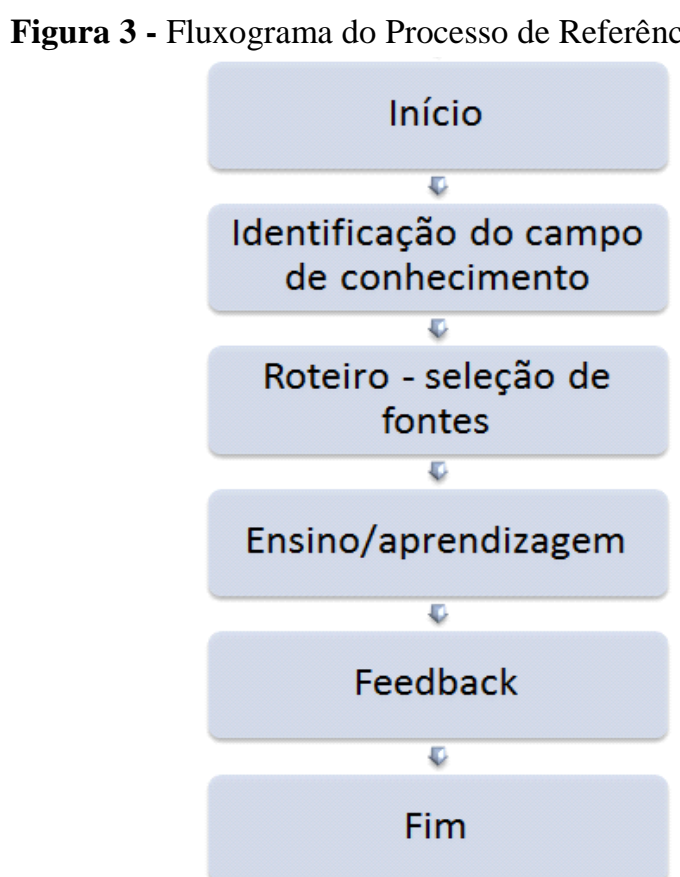

Fonte: Pintro (2012, p. 84) baseado em Rostirolla (2006) 
Revista ACB: Biblioteconomia em Santa Catarina, Florianópolis, v. 22, n. 2, ESPECIAL, p. 329-342, abr./ jul., 2017.

Anais do $35^{\circ}$ Painel Biblioteconomia Santa Catarina.

Chapecó

Cada uma das etapas do PRE foi caracterizada, para que em seguida pudessem ser relacionadas as competências necessárias. O Quadro 1 apresenta, de forma sucinta, as principais características das etapas do PRE.

Quadro 1-Caracterização das etapas do processo de referência educativo

\begin{tabular}{|c|c|}
\hline ETAPA & CARACTERÍSTICAS \\
\hline $\begin{array}{l}\text { Identificação do campo de } \\
\text { conhecimento }\end{array}$ & $\begin{array}{ll}\text { - } & \text { Identificação das necessidades informacionais. } \\
\text { - } & \text { Entrevista prévia. } \\
\text { - } & \text { Conhecimento da demanda, utilizando indicadores de comportamento. }\end{array}$ \\
\hline $\begin{array}{l}\text { Roteiro - seleção de } \\
\text { fontes }\end{array}$ & $\begin{array}{l}\text { - Seleção das fontes que serão acessadas e demonstradas e das palavras-chave } \\
\text { pertinentes ao tema ou área de interesse dos usuários. } \\
\text { - Tomada de decisão. } \\
\text { - } \quad \text { Exploração e tratamento de fontes de informação; manuseio de sistemas } \\
\text { automatizados. }\end{array}$ \\
\hline $\begin{array}{l}\text { Ensino/ } \\
\text { Aprendizagem }\end{array}$ & $\begin{array}{l}\text { - } \quad \text { Ensino efetivo sobre o acesso e uso das fontes e recursos informacionais selecionados. } \\
\text { - } \quad \text { Educação de usuários. } \\
\text { - } \quad \text { Ambiente de estímulo ao aprendizado dos usuários. } \\
\text { - } \quad \text { Transmissão de informações efetivas. } \\
\text { - Compartilhamento dos conhecimentos. }\end{array}$ \\
\hline Feedback & $\begin{array}{ll}\text { - } & \text { Avaliação do ensino-aprendizagem. } \\
\text { - } & \text { Regulador do processo. }\end{array}$ \\
\hline
\end{tabular}

Fonte: Pintro (2012, p. 179)

A caracterização das etapas do PRE permitiu a definição das competências (Conhecimentos, Habilidades e Atitudes) relacionadas e necessárias ao bibliotecário para o desenvolvimento de suas funções em cada uma delas, conforme pode ser verificado no Quadro 2, a seguir.

Quadro 2 - Competências relacionadas ao bibliotecário em cada etapa do processo de referência tradicional

\section{ETAPA CARACTERÍSTICAS \\ CHA BIBLIOTECÁRIO}

\begin{tabular}{|c|c|c|}
\hline \multirow{3}{*}{$\begin{array}{l}\text { Identificação do } \\
\text { campo de } \\
\text { conhecimento }\end{array}$} & \multirow{3}{*}{$\begin{array}{l}\text {-Identificação das necessidades } \\
\text { informacionais. } \\
\text { •Entrevista prévia. } \\
\text { Conhecimento da demanda, } \\
\text { utilizando indicadores de } \\
\text { comportamento. }\end{array}$} & $\begin{array}{l}\text { - Técnicas de entrevista; } \\
\text { - Terminologia }\end{array}$ \\
\hline & & $\begin{array}{l}\text { Habilidades } \\
\text { - Capacidade de comunicação oral e escrita; } \\
\text { - Compreensão da necessidade e das expectativas do usuário; } \\
\text { - Compreensão de tipos psicológicos; } \\
\text { - Perspicácia; } \\
\text { - Utilizar linguagem acessível ao usuário. }\end{array}$ \\
\hline & & Atitudes \\
\hline
\end{tabular}


Revista ACB: Biblioteconomia em Santa Catarina, Florianópolis, v. 22, n. 2, ESPECIAL, p. 329-342, abr./ jul., 2017. Anais do $35^{\circ}$ Painel Biblioteconomia Santa Catarina.

Chapecó

\begin{tabular}{|c|c|c|}
\hline & & $\begin{array}{l}\text { - Atenção ao usuário; } \\
\text { - Confiabilidade; } \\
\text { - Cortesia; } \\
\text { - Diplomacia; } \\
\text { - Empatia; } \\
\text { - Humildade; } \\
\text { - Pró-atividade. }\end{array}$ \\
\hline \multirow{3}{*}{$\begin{array}{l}\text { Roteiro - } \\
\text { seleção de } \\
\text { fontes }\end{array}$} & \multirow{3}{*}{$\begin{array}{l}\text { •Seleção das fontes que serão } \\
\text { acessadas e demonstradas e das } \\
\text { palavras-chave pertinentes ao } \\
\text { tema ou área de interesse dos } \\
\text { usuários. } \\
\text { •Tomada de decisão. } \\
\text { •Exploração e tratamento de } \\
\text { fontes de informação; manuseio } \\
\text { de sistemas automatizados. }\end{array}$} & $\begin{array}{l}\text { - Fontes de informação; } \\
\text { - Línguas estrangeiras; } \\
\text { - Organização da informação; } \\
\text { - Tecnologias da informação; } \\
\text { - Terminologia. }\end{array}$ \\
\hline & & $\begin{array}{ll} & \text { Habilidades } \\
\text { - Discernimento; } & \\
\text { - Elaboração de manuais; } \\
\text { - Planejamento; } \\
\text { - Pontualidade. }\end{array}$ \\
\hline & & $\begin{array}{l}\text { Atualização constante; } \\
\text { - Senso crítico. }\end{array}$ \\
\hline \multirow{3}{*}{$\begin{array}{l}\text { Ensino/ } \\
\text { Aprendizagem }\end{array}$} & \multirow{3}{*}{$\begin{array}{l}\text { •Ensino efetivo sobre o acesso e } \\
\text { uso das fontes e recursos } \\
\text { informacionais selecionados. } \\
\text { •Educação de usuários. } \\
\text {-Ambiente de estímulo ao } \\
\text { aprendizado dos usuários. } \\
\text {-Transmissão de informações } \\
\text { efetivas. } \\
\text { •Compartilhamento dos } \\
\text { conhecimentos. }\end{array}$} & $\begin{array}{l}\text { - Fontes de informação; } \\
\text { - Línguas estrangeiras; } \\
\text { - Metodologia científica; } \\
\text { - Métodos, técnicas e ferramentas de coleta; } \\
\text { - Organização da informação; } \\
\text { - Tecnologias da informação; } \\
\text { - Terminologia. }\end{array}$ \\
\hline & & $\begin{array}{l}\text { Habilidades } \\
\text { - Agilidade; } \\
\text { - Capacidade de comunicação oral e escrita; } \\
\text { - Compreensão da necessidade e das expectativas do usuário; } \\
\text { - Compreensão de tipos psicológicos; } \\
\text { - Equilíbrio emocional; } \\
\text { - Utilizar linguagem acessível ao usuário. }\end{array}$ \\
\hline & & $\begin{array}{l}\text { - Atenção ao usuário; } \\
\text { - Atualização constante; } \\
\text { - Confiabilidade; } \\
\text { - Cortesia; } \\
\text { - Criatividade; } \\
\text { - Diplomacia; } \\
\text { - Empatia; } \\
\text { - Flexibilidade; } \\
\text { - Humildade; } \\
\text { - Motivação. }\end{array}$ \\
\hline & & $\begin{array}{ll}\text { - Metodologia científica. } & \text { Conhecimentos }\end{array}$ \\
\hline
\end{tabular}




\begin{tabular}{|c|c|c|}
\hline \multirow[t]{2}{*}{ Feedback } & \multirow{2}{*}{$\begin{array}{l}\text { •Avaliação do ensino- } \\
\text { aprendizagem. } \\
\text { •Regulador do processo. }\end{array}$} & $\begin{array}{l}\text { Habilidades } \\
\text { - Aprendizado com as experiências; } \\
\text { - Capacidade de comunicação oral e escrita; } \\
\text { - Equilíbrio emocional; } \\
\text { - Negociação; } \\
\text { - Utilizar linguagem acessível ao usuário. }\end{array}$ \\
\hline & & $\begin{array}{l}\text { - Atenção ao usuário; } \\
\text { - Confiabilidade; } \\
\text { - Criatividade; } \\
\text { - Diplomacia; } \\
\text { - Empatia; } \\
\text { - Flexibilidade; } \\
\text { - Senso crítico. }\end{array}$ \\
\hline
\end{tabular}

Fonte: Pintro (2012, p. 179)

Destaca-se que as unidades de informação são organizações prestadoras de serviços e por isso necessitam estabelecer sistemas de gestão visando a melhoria e a qualidade destes serviços, bem como garantir que seus usuários tenham a percepção desta qualidade. Com o levantamento das competências do bibliotecário de referência no PRE é possível inferir que, de fato, o processo de referência educativo é consequência da evolução das Tecnologias de Informação e Comunicação; tanto a biblioteca universitária como a execução das atividades do bibliotecário de referência também são transformadas.

Outra contribuição, esta pesquisa conseguiu identificar lacunas nas competências apresentadas pelos bibliotecários respondentes, tais como: o conhecimento de "Línguas estrangeiras", a habilidade na "Elaboração de manuais" e a atitude de "Atualização constante". De acordo com a literatura estudada para o desenvolvimento dessa pesquisa, essas lacunas influenciam diretamente na qualidade dos serviços prestados, visto que o desenvolvimento das competências está ligado à melhoria dos padrões de qualidade e, consequentemente, ao diferencial competitivo.

Ademais, sugere-se que sejam priorizadas em busca da melhoria necessária para alcançar padrões de qualidade, uma vez que, conforme Pintro (2012), para a qualidade dos serviços é fundamental desenvolver as competências inexistentes ou deficientes e aperfeiçoar aquelas que já existem.

\section{CONCLUSÕES}

O serviço de referência das Bibliotecas Universitárias passa por transformações decorrentes do avanço do processo de referência educativo (PRE), caracterizado pelas atividades desenvolvidas pelo 
Revista ACB: Biblioteconomia em Santa Catarina, Florianópolis, v. 22, n. 2, ESPECIAL, p. 329-342, abr./ jul., 2017.

Anais do $35^{\circ}$ Painel Biblioteconomia Santa Catarina.

Chapecó

bibliotecário com a finalidade de capacitar e treinar os usuários para a utilização de recursos e fontes informacionais, de forma que consigam suprir suas próprias demandas informacionais.

O PRE é decorrente do grande avanço das tecnologias de informação e comunicação (TIC) e esse novo contexto, que redimensionou as funções do bibliotecário, exige também uma transformação nas competências necessárias a esse profissional para a execução das novas atividades.

Dessa forma, este estudo propôs a definição de um conjunto pertinente de competências necessárias ao bibliotecário atuante no PRE para o desenvolvimento de suas atividades, levando em consideração as características específicas das etapas desse processo.

Destaca-se que esse conjunto de competências foi definido com base em ampla revisão bibliográfica na área em questão. Possíveis lacunas existentes nessas competências podem afetar diretamente a qualidade dos serviços prestados no PRE.

Esta pesquisa contribui para o aperfeiçoamento dos serviços prestados por unidades de informação que já passaram ou passam por transformações no serviço de referência e desenvolvem atividades relacionadas ao PRE.

Como sugestão de estudos futuros, recomenda-se a verificação da percepção do usuário das unidades de informação quanto às competências necessárias ao bibliotecário atuante no PRE.

\section{REFERÊNCIAS}

ABECKER, Andreas et al. The decor toolbox for workflow-embedded organizational memory access. In: International Conference on Enterprise Information Systems ICEIS, 3, 2001, Setúbal, Portugal.

Proceedings... Setúbal: ICEIS, 2001. Disponível

em:<http://citeseerx.ist.psu.edu/viewdoc/summary?doi=10.1.1.29.3547\&ran> . Acesso em: 26 abr. 2011.

ALEXIM, João Carlos; BRÍGIDO, Raimundo (Org.). Glossário de termos técnicos: certificação e avaliação de competências. Brasília: OIT, 2002. Disponível em:<http://www.oit.org.br/content/certifica\%C3\%A7\%C3\%A3o-de-compet\%C3\%AAnciasprofissionais-gloss\%C3\%A1rio-de-termos-t\%C3\%A9cnicos>. Acesso em: 22 mar. 2017.

ALVES, Maria Bernardete Martins; FAQUETTI, Marouva Fallgatter. Mudanças no serviço de referência, em bibliotecas universitárias, sob o impacto das novas tecnologias. In: SEMINÁRIO NACIONAL DE BIBLIOTECAS UNIVERSITÁRIAS, 12., 2002, Recife. Anais... Disponível em: </https://repositorio.ufsc.br/handle/123456789/170782>. Acesso em: 22 mar. 2017. 
Revista ACB: Biblioteconomia em Santa Catarina, Florianópolis, v. 22, n. 2, ESPECIAL, p. 329-342, abr./ jul., 2017. Anais do $35^{\circ}$ Painel Biblioteconomia Santa Catarina.

Chapecó

ALVES, Ana Paula Meneses; VIDOTTI, Silvana Aparecida Borsetti Gregório. O serviço de referência e informação digital. Biblionline, João Pessoa, v. 2, n. 2, 2006. Disponível em:

<2/http://periodicos.ufpb.br/ojs2/index.php/biblio/article/viewFile/611/448>. Acesso em: 22 mar. 2017.

AMARAL, Roniberto Morato do et al. Modelo para o mapeamento de competências em equipes de inteligência competitiva. Ciência da Informação, Brasília, v. 37, n. 2, p. 7-19, maio/ago. 2008.

Disponível em:<http://www.scielo.br/pdf/ci/v37n2/a01v37n2.pdf>. Acesso em: 20 mar. 2017.

ARRUDA, Maria da Conceição Calmon; MARTELETO, Regina Maria; SOUZA, Donaldo Bello de. Educação, trabalho e o delineamento de novos perfis profissionais: o bibliotecário em questão. Ciência da Informação, Brasília, v. 29, n. 3, p. 14-24, set./dez. 2000. Disponível em:<http://www.scielo.br/pdf/ci/v29n3/a02v29n3.pdf>. Acesso em: 20 mar. 2017.

ASSIS, Marisa de. A educação e a formação profissional na encruzilhada das velhas e novas tecnologias. In: FERRETI, Celso João et al. (Org.). Novas tecnologias, trabalho e educação: um debate multidisciplinar. 8. ed. Petrópolis: Vozes, 2002.

BRANDÃO, Hugo Pena; GUIMARÃES, Tomás de Aquino. Gestão de competências e gestão de desempenho: tecnologias distintas ou instrumentos de um mesmo construto? RAE: Revista de Administração de Empresas, São Paulo, v. 41, n. 1, p. 8-15, jan./mar. 2001. Disponível em: <nnahttp://www.scielo.br/pdf/rae/v41n1/v41n1a02.pdf>. Acesso em: 22 mar. 2017

DAVENPORT, Thomas H.; JARVENPAA, Sirkka L.; BEERS, Michael C. Improving Knowledge Work Processes. Sloan Management Review, v. 37, n. 4, Summer 1996.

CUNHA, Murilo Bastos da. Construindo o futuro: a biblioteca universitária brasileira em 2010. Ciência da Informação, Brasília, v. 29, n. 1, p. 71-89, jan./abr. 2000. Disponível

em: <http://w.scielo.br/pdf/ci/v29n1/v29n1a8.pdf > . Acesso em: 22 mar. 2017.

DURAND, Thomas. Forms of incompetence. In: INTERNATIONAL CONFERENCE ON COMPETENCE-BASED MANAGEMENT, 4., 1998, Oslo. Proceedings... Oslo: Norwegian School of Management, 1998.

DURAND, Thomas. L'alchimie de la Compétence. Revue Française de Gestion, Paris, n. 127, p. 84102, jan./fév. 2000.

FERREIRA, Maria Isabel Goulão de Matos. High tech/high toch: serviço de referência e mediação humana. In: CONGRESSO NACIONAL DE BIBLIOTECÁRIOS, ARQUIVISTAS E DOCUMENTALISTAS, 8., 2004, Estoril, Portugal. Anais... Estoril: Associação Portuguesa de Bibliotecários, Arquivistas e Documentalistas, 2004. Disponível em:<http://www.apbad.pt/Edicoes/EdicoesCongresso8.htm> . Acesso em: 02 fev. 2011.

FLEURY, Afonso; FLEURY, Maria Tereza Leme. Estratégias empresariais e formação de competências: um quebra-cabeça caleidoscópio da indústria brasileira. São Paulo: Atlas, 2000.

GIL, Antonio Carlos. Métodos e técnicas de pesquisa social. 6. ed. São Paulo: Atlas, 2008.

GROGAN, Denis. A prática do serviço de referência. Brasília: Briquet de Lemos, 1995. 
Revista ACB: Biblioteconomia em Santa Catarina, Florianópolis, v. 22, n. 2, ESPECIAL, p. 329-342, abr./ jul., 2017. Anais do $35^{\circ}$ Painel Biblioteconomia Santa Catarina.

Chapecó

LISTON, Rose Cristiani Franco Seco; SANTOS, Plácida da Costa. Representando a Information Literacy "Competências Informacionais" na Biblioteconomia. Em Questão, Porto Alegre, v. 14, n. 2, p. 287-300, jul./dez. 2008. Disponível em: </http://seer.ufrgs.br/EmQuestao/article/view/5043/4742>. Acesso em: 20 mar. 2017.

MAPONYA, Pearl M. Knowledge management practices in academic libraries: a case study of the University of Natal, Pietermaritzburg Libraries. Pietermaritzburg: University of KwaZuluNatal, 2004.

NUNES, Sueli; SANTOS, Luciana. Políticas de informação e aprendizagem organizacional: desafios para a implantação de novas tecnologias em bibliotecas universitárias. Comunicação e Informação, v. 10, $\mathrm{n}$. 1, p. 73-81, jan./jun. 2007. Disponível em: </http://www.revistas.ufg.br/ci/article/view/10311/7160>. Acesso em: 22 mar. 2017.

PINTRO, Sirlene. Serviço de referência em bibliotecas universitárias: um estudo de competências e qualidade. 2012. 231 f. Dissertação (Mestrado em Ciência da Informação) - Programa de Pós-Graduação em Ciência da Informação da Universidade Federal de Santa Catarina, Florianópolis, 2012.

PINTRO, Sirlene; INOMATA, Danielly Oliveira; VARVAKIS, Gregório. Serviço de referência de Bibliotecas Universitárias: tradicional e educativo. Tendências da Pesquisa Brasileira em Ciência da Informação, v. 7, p. 140-159, 2014. Disponível em:

</http://inseer.ibict.br/ancib/index.php/tpbci/article/viewFile/158/198>. Acesso em: 22 mar. 2017.

ROPÉ, Françoise; TANGUY, Lucie. Saberes e competências: o uso de tais noções na escola e na empresa. Campinas: Papirus, 1997.

ROSTIROLLA, Gelci. Gestão do conhecimento no serviço de referência em bibliotecas universitárias: uma análise com foco no processo de referência. 2006. 174 f. Dissertação (Mestrado em Ciência da Informação) - Programa de Pós-Graduação em Ciência da Informação da Universidade Federal de Santa Catarina, Florianópolis, 2006.

SCHREIBER, Guus et al. Knowledge Engineering and Management: The CommonKADS Methodology. Cambridge : MIT Press, 2000.

SEO, Wonchul et al. A state-driven modeling approach to human interactions for knowledge intensive services. Expert Systems with Applications, v. 38, n. 3, p. 1917-1930, mar. 2011

SILVA, Patrícia Maria. Sistemas de informação em bibliotecas: o comportamento dos usuários e bibliotecários frente às novas tecnologias de informação. Revista Digital de Biblioteconomia e Ciência da Informação, Campinas, v. 5, n. 2, p. 1-24, jan./jun. 2008. 


\title{
COMPETENCES OF THE LIBRARIAN IN THE EDUCATIONAL REFERENCE PROCESS OF UNIVERSITY LIBRARIES
}

\begin{abstract}
The reference service is one of the core activities of libraries and undergoes major transformations due to technological advances. In this context, librarians working in the reference service take on new functions, which require the development of new competencies so that they can develop their activities with quality. Taking into account these aspects, it was relevant to investigate the competencies needed by the librarian who is active in this aspect of the reference service that is progressively expanding, the educational reference process. The stages of the reference and educational process were identified and characterized and the necessary competencies were defined for the reference librarian in each of the stages. It is concluded that the defined set of competencies contributes to the improvement of the services provided by information units that develop the educational reference process.
\end{abstract}

Keywords: Reference service. Educational reference process. Competencies.

\section{SIRLENE PINTRO}

Doutoranda em Ciência da Informação pelo Programa de Pós-Graduação em Ciência da Informação da Universidade Federal de Santa Catarina (PGCIN/UFSC). Mestre em Ciência da Informação pelo Programa de PósGraduação em Ciência da Informação da Universidade Federal de Santa Catarina (PGCIN/UFSC). Graduada em Biblioteconomia pela Universidade Federal de Santa Catarina (UFSC). Pesquisadora do Núcleo de Gestão para a Sustentabilidade (NGS-UFSC). E-mail: sirlene23@gmail.com

\section{GREGÓRIO VARVAKIS}

Doutor em Manufacturing Engineering pela Loughborough University of Technology (LBORO- Inglaterra). Mestre em Engenharia de Produção pela Universidade Federal de Santa Catarina (UFSC). Graduado em Engenharia Mecânica pela Universidade Federal do Rio Grande do Sul (UFRGS). Mestre em Engenharia de Produção pela Universidade Federal de Santa Catarina (UFSC). Professor titular da Universidade Federal de Santa Catarina, Depto de Engenharia do Conhecimento. E-mail: g.varvakis@ufsc.br

\section{DANIELLY OLIVEIRA INOMATA}

Doutoranda em Ciência da Informação pela Universidade Federal de Santa Catarina (PGCIN/UFSC). Mestre em Ciência da Informação pela Universidade Federal de Santa Catarina (PGCIN/UFSC). Especialista em Planejamento e Gerenciamento de Águas pela Universidade Federal do Amazonas (UFAM). Graduada em Biblioteconomia pela Universidade Federal do Amazonas (UFAM). Atua como pesquisadora no Grupo de Estudo e Pesquisa em Ciência da Informação (UFAM), no Grupo de Pesquisa: Informação, Tecnologia e Sociedade (UFSC) e no Núcleo de Gestão para Sustentabilidade - NGS (UFSC). É consultora AdHoc da Fundação de Amparo à Pesquisa do Estado do Amazonas (FAPEAM). Atuou como professora conteudista em Educação à Distância. E-mail: inomata.danielly@gmail.com 